\title{
PERSISTÊNCIA DOS HERBICIDAS IMAZAQUIN E IMAZETHAPYR NO SOLO E OS EFEITOS SOBRE PLANTAS DE MILHO E PEPINO'.
}

\author{
DIONÍSIO L. P. GAZZIERO ${ }^{2}$, DÉCTO KARAN ${ }^{2}$, ELEMAR VOLL ${ }^{2}$ c ADOLFO ULBRICH ${ }^{3}$
}

\section{RESUMO}

Dois experimentos foram instalados em Londrina, PR, com o objetivo de avaliar a persistência dos herbicidas imazaquin e imazethapyr no solo, aplicados eM pré emergência e pré e pós emergência. respectivamente. Nas subparcelas foram usados imazaquin nas doses de 0,12: 0,15 (normal) e $0,30 \mathrm{~kg} / \mathrm{ha}$ e imazethapyr nas doses de 0,1 (normal) e $0,2 \mathrm{~kg} / \mathrm{ha}$. Nos blocos foram distribuídos seis épocas de semeadura: 0, 30, 60, 90, 120 e 150 dias após a aplicação (DAA). A atividade residual foi avaliada com a semeadura do milho Pioneer 3072, no campo, e do pepino em casa de vegetação. Os resultados foram descritos com base nas avaliações visuais de fitotoxicidade e hiomassa seca das plantas de milho e da hiomassa seca e altura das plantas de pepino. A fitotoxicidade de imazaquin e de imazethapyr não foi considerada prejudicial às plantas de milho. quando a semeadura ocorreu 90 dias após as suas aplicações, respectivamente em pré e pós-emergência. As plantas de pepino mostraramse mais sensíveis aos herbicidas do que as plantas de milho, especialmente ao imazaquin. Para imazaquin, nas doses normais, os sintomas desapareceram aos 120 dias após aplicação. No mesmo período, para imazethapyr, na menor dose, ocorreu recuperação da altura das plantas de pepino, mas não do seu peso.

Palavras chaves: Resíduo. bioensaio, fitotoxicidade, Zea mays, Cucumis sativus.

\section{ABSTRACT \\ Persistence of imazaquin and imazethapy $r$ in the soil, and their effects on corn and cucumber plants}

The persistence of imazaquin (preemergence) and imazethapyr (pre and postemergence) in the soil, and their effects on corn and cucumber plants were evaluated in two expriments in Londrina, Paraná State. Treatments of imazaquin 0,12, 0,15 (normal) and 0,30 kg./ha, and imazethapyr 0,1 (normal) and $0,2 \mathrm{~kg} / \mathrm{ha}$ were arranged in a split-plot design. Six sowing dates (plots), including 0, 30, 60, 90120 and 150 days after herbicide application (DAA) were arranged in blocks. Residual activity for corn (Pioneer
3072) was evaluated in the field, and for cucumber in a bioassay, in greenhouse. Corn plant phythotoxicity was visually evaluated and dry weight were recorded as well as dry weight and height for cucumber plants. Imazaquin (preemergence) and imazethapyr (pre and postemergence) phytotoxicity were not considered to be harmful to corn plants, when sowing occurred 90 DAA. Cucumber plants showed to be more sensitive to the herbicides than corn plants, especially to imazaquin. Symptoms disappeared

1Aceito para publicação em 20/01/97 e na forma revisada em 13/10/97.

2 Eng $^{\circ}$ Agro $^{\circ}$. Pesquisador da tmbrapa Soja. Caixa postal 231. CEP 86001-970. Londrina/PR

$3 \mathrm{Eng}^{\circ} \mathrm{Agr}^{\circ}$. Mestrando da UEL. Caixa Postal 6001. CEP 86051-970. Londrina/PR 
120 DAA for imazaquin, at normal dosis. After the same period, cucumber plant height recovered from imazethapyr phytotoxicity at the lowest

\section{INTRODUÇÃO}

Os herbicidas imazaquin e imazethapyr tem sido utilizados com frequência, no controle de plantas daninhas da cultura da soja. A absorção destes produtos ocorre tanto por via radicular como foliar e a translocação se dá pelo floema e xi le ma, ac umul ando-se nos meristemas de crescimento das invasoras, onde provocam necrose.

Esses herbicidas possuem característica de persistir no solo. Se por um lado isto é favorável, por proporcionar controle residual durante todo o ciclo da soja, por outro pode constituir-se em risco para culturas sucessivas. Essa característica, no entanto, tem causado preocupação aos agricultores que praticam a rotação de culturas, e principalmente aqueles que cultivam o milho safrinha, em sucessão à soja. Para Vidal e Fleck (1994), os produtos apresentam potencialidade para causar danos também ao girassol, cultivado em rotação com a soja, sendo seu maior efeito na redução do número de plantas (Fleck e Vidal, 1994).

Em estudos de dissipação, Loux et al. (1989) verificaram que aproximadamente $80 \%$ do ingrediente ativo desses produtos é degradado com cerca de 60 dias e que o restante pode exceder a 160 dias. Em solos argilosos com alto teor de matéria orgânica, a dis sipação é menor Loux et al. (1989) Vários são os fatores que influenciam a persistência de imazaquin e imazethapyr. Solos com boas condições de umidade promovem dissipação mais rápida (Loux e Reese, 1993), assim como raios ultra-violeta e infra-vermelho também provocam degrad ação mais rápida (Bashan e Lavy 1987 e Curran et al., 1982). Isto pode explicar a menor persistência quando o produto é aplicado em pré-emergência dosis, but not its weight.

Key words: Residue, bioassay, phytotoxicity, Zea mays, Cucumis sativus.

em comparação com a aplicação em pré-plantio e incorporado.

Recomenda-se um intervalo de 300 dias entre a aplicação de imazaquin ou imazethapyr e a semeadura do milho em rotação, por questões de segurança, uma vez que não existem informações, sobre o assunto, no Brasil. No entanto, quando se cultiva o milho "safrinha", este intervalo é reduzido para, aproximadamente, 120-150 dias.

A preocu pação que se coloca é se a persistência dos produtos pode afetar e a que nível a produção do milho "safrinha". O objetivo do presente trabalho foi determinar a curva de degradação dos herbicidas imazaquin e imazathapyr, bem como a influência desses produtos sobre as plantas de milho (Pioneer-3072) e de pepino.

\section{MATERIAL E MÉTODOS}

Dois experimentos foram instalados na fazenda da Embrapa-Soja em Londrina, PR, na safra 1993/94. Um experime nto foi instalado a campo, onde foram aplicados os produtos imazaquin e imazethapyr na cultura da soja e em seguida, de acordo com cada tratamento, foi semeado o milho híbrido Pioneer 3072 como espécie reagente, em seis diferentes épocas. O ou tro experimento foi in stal ado em casa de vegetação, utilizando o solo coletado no primeiro experimento usando plantas de pepino como espécie reagente.

O solo foi descrito como terra roxa estruturada com $75 \%$ de argila e $2,7 \%$ de matéria orgânica. Foi utilizado o delineamento experimental de blocos ao acaso, arranjados em

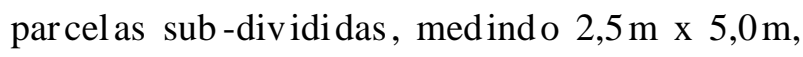
com quatro repetições. Nas parcelas foram distribuídos os produtos imazaquin nas doses de 
0,$12 ; 0,15$ (normal) e $0,30 \mathrm{~kg} / \mathrm{ha}$, aplicado em préemergência, e imazethapyr, nas doses de 0,10 (normal) e $0,20 \mathrm{~kg} / \mathrm{ha}$, aplicado em pré e pós emergência. Nas subparcelas foram distribuídas, aleat oriamente, seis épocas de semeadura de milho, de 0, 30, 60, 90, 120 e 150 dias após a aplicação de cada produto.

O preparo de solo utilizado foi na forma convencional (aração + gradagem). Foi semeada a soja cultivar BR-29, adubada com $250 \mathrm{~kg}$ da fórmula 0 - 20 - 20 e aplicados os herbicidas e doses já descritas. De 30 em 30 dias, a partir da aplicação (zero dia) a soja foi eliminada e semeado o milho híbrido Pioneer 3072. Para cada época de semeadura foram realizad as três avaliações de fitotoxicidade: 14, 28 e 42 dias após a se meadura (DAS) e da biomassa seca das plantas de milho. A escala utilizada foi a porcentual (0 - 100\%), onde zero significou nenhuma sintoma e $100 \%$ a morte total das plantas. Estabeleceu-se 30\% como o limite crítico, a part ir do qual foi estimado que os danos provocados poderiam refletir, de forma irreversível, na produção.

A aplicação dos produtos foi feita com pulverizador de precisão a $\mathrm{CO}$, com volume de calda de 250 litros/ha. A temperatura do ar variou de $30^{\circ} \mathrm{C}$ a $33^{\circ} \mathrm{C}$ durante as aplicações e a umidade relativa do ar de $68 \%$ a $74 \%$. A umidade do solo era adequada. Os tratamentos com imazethapyr, em pós-mergência, foram aplicados 11 dias após a semeadura.

O segundo experimento foi conduzido em casa de vegetação, utilizando como substrato o solo coletado no dia da semeadura do milho de cada tratamento. Com o auxílio de um trado, oito subamostras foram coletadas a $5 \mathrm{~cm}$ de profundidade, para a composição da amostra principal. O solo foi congelado e conservado até o final do primeiro experimento, quando foram colocados em vasos plásticos de $200 \mathrm{ml}$. Esses vasos foram dispostos no mesmo delineamento e número de repetições utilizadas no experimento de campo. Utilizou -se a cultura do pepino (Cucumis sativus) como planta reagente. As avaliações constaram da observação da altura e da biomassa seca das plantas aos 14 e 28 dias da se me ad ura. Em am bos os ex periment os as variáveis foram analisadas estatisticamente.

\section{RESULTADOS E DISCUSSÃO}

O balanço hídrico decendial realizado no período de instalação do experimento à campo mostra ter ocorrido excedente hídrico a partir do final de novembro até o inicio de março, mês em que se registrou déficit hídrico. Este déficit voltou a ser registrado entre o final de abril e o final de maio, a partir do qual houve novamente excedente hídrico.

Das três avaliações (14, 28 e 42 DAS) realizadas em cada época de se meadura, considerou-se que a dos 28 DAS foi a mais representativa dos resultados obtidos, por melhor ex pressar a interferência dos produtos no desenvolvimento das plantas. Dessa forma serão apresentados e discutidos os gráficos dessa avaliação. Embora a dose de imazaquin recomendada seja de $0,15 \mathrm{~kg} / \mathrm{ha}$, os agricultores utilizam, com frequência, a dose de $0,12 \mathrm{~kg} / \mathrm{ha}$, vi sando re duzir en tre ou tros fatores a sua persistência no solo.

No primeiro experimento, aos 28 DAS, foi observado que quando o milho foi semeado no dia da aplicação de imazaqui na dosagem de 0,12 $\mathrm{kg} / \mathrm{ha}$, o percentual de fitotoxicidade foi próximo a $75 \%$. Nas semeaduras realizadas posteriormente a fitotoxicidade foi gradativamente menor com o passar do tempo. Aos 90 DAA o dano registrado foi inferior a $30 \%$, com os sintomas desaparecendo totalmente aos 120 dias (Figura 1). Comparativamente, na dose normal de $0,15 \mathrm{~kg} / \mathrm{ha}$, a fitotoxicidade atingiu $90 \%$, portanto superior àquela registrada com a dose $0,12 \mathrm{~kg} / \mathrm{ha}$, com os sintomas desaparecendo em aproximadamente 120 dias. O dobro da dose normal provocou nas plantas fitotoxicidade ainda maior, e aos 150 dias os sintomas também desapareceram. Resultados 

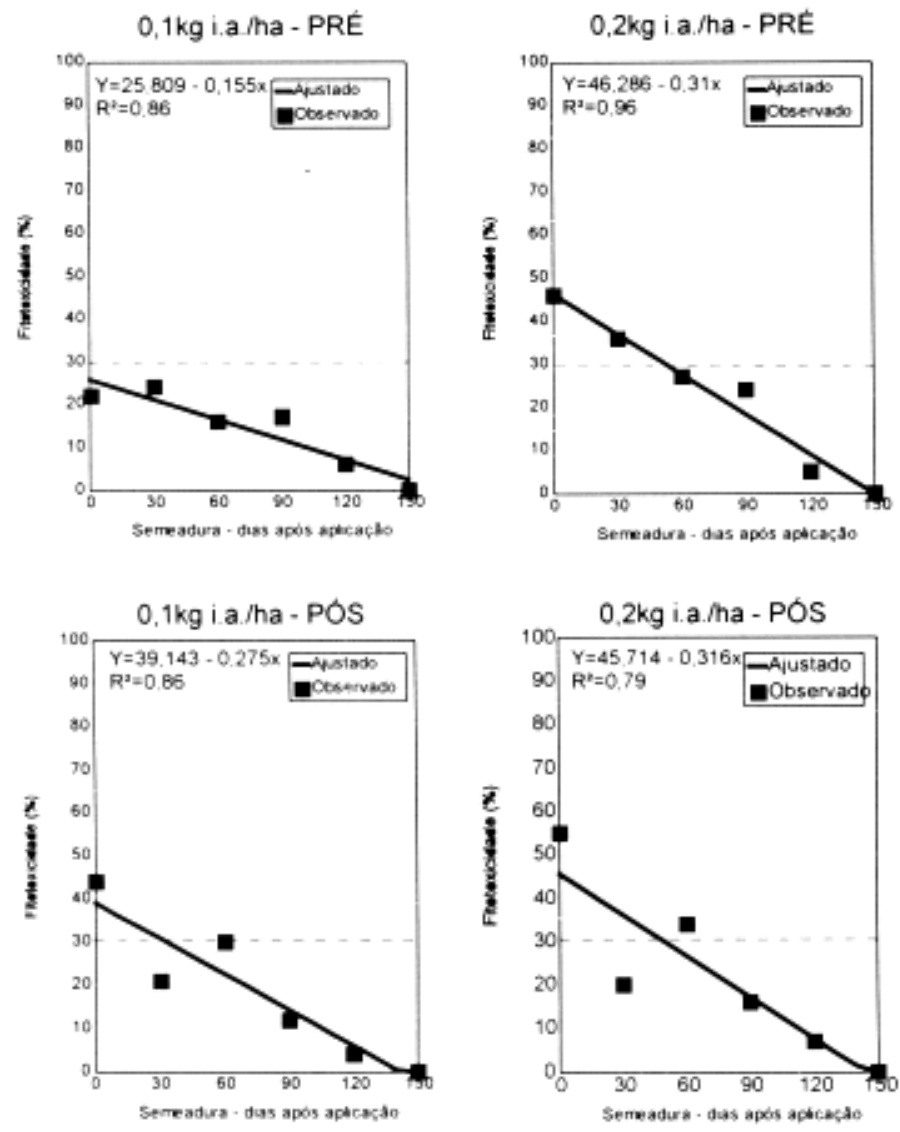

FIGURA 2. Avaliação do efeito da persistência de imazethapyr aplicado em pré e pós-emergência, sobre a cult ura do milho híbrido P-3072, cultivado em safrinha. Realizada aos 28 dias após a semeadura. Embrapa Soja. Londrina - PR, 1997.

As médias da biomassa seca por planta de mi lho nas cinco ép ocas de avaliação são apresentadas na Tabela L A sexta época foi afetada por ocorrência de geadas o que inviabilizou a avaliação. Verificou-se efeito severo de todas as doses de imazaquin sobre as plantas de milho quando semeadas imediatamente após a aplicação do produto (0 dias). Na maior dose, os efeitos severos ainda persistiam aos 30 dias. Estatisticamente não foram obse rvadas diferenças na biomassa seca aos 60 DAA, mas sugere-se intervalo mínimo de 90 a 120 DAA para o plantio do milho, por que stão de segurança. Deve-se ressaltar que a diferença de peso observada nas colunas de 0 a 120 DAS é devida ao efeito época de semeadura que tende a reduzir à partir de 15 de outubro. $\mathrm{O}$ baixo peso obtido no tratamento com o dobro da dose de imaze thapyr aos 120 dias em pós-emergência é provavelmente devido a outros fatores não ligados ao tratamento aplicado. 
TABELA 1. Média da biomassa seca por planta de milho, sob diferentes épocas de semeadura, em resposta à aplicação dos produtos imazaquin e imazethapyr. Embrapa Soja. Londrina PR, 1997.

\begin{tabular}{lccccccc}
\hline PRODUTO & i.a. & APLICAÇÃO & \multicolumn{3}{c}{ MÉDIA } & DA & BIOMASSA SECA (g/planta) \\
\cline { 4 - 7 } & $\mathbf{k g} / \mathbf{h a}$ & & $\mathbf{0} /^{\mathbf{1}}$ & $\mathbf{3 0}$ & $\mathbf{6 0}$ & $\mathbf{9 0}$ & $\mathbf{1 2 0} \mathbf{2}^{\mathbf{2}}$ \\
\hline Testemunha & -- & -- & $35,56 \mathrm{a} /{ }^{\mathbf{3}}$ & $13,90 \mathrm{ab}$ & $8,39 \mathrm{a}$ & $13,63 \mathrm{~b}$ & $7,30 \mathrm{ab}$ \\
Imazaquin & 0,12 & PRÉ & $0 \mathrm{~b}$ & $11,24 \mathrm{~b}$ & $8,31 \mathrm{a}$ & $14,51 \mathrm{~b}$ & $7,79 \mathrm{ab}$ \\
Imazaquin & 0,15 & PRÉ & $0 \mathrm{~b}$ & $10,31 \mathrm{~b}$ & $6,60 \mathrm{a}$ & $14,48 \mathrm{~b}$ & $9,88 \mathrm{a}$ \\
Imazaquin & 0,30 & PRÉ & $0 \mathrm{~b}$ & $3,89 \mathrm{c}$ & $4,38 \mathrm{a}$ & $14,00 \mathrm{~b}$ & $9,10 \mathrm{a}$ \\
Imazethapyr & 0,10 & PÓS & $32,00 \mathrm{a}$ & $18,43 \mathrm{a}$ & $8,06 \mathrm{a}$ & $19,20 \mathrm{ab}$ & $2,55 \mathrm{bc}$ \\
Imazethapyr & 0,20 & PÓS & $31,71 \mathrm{a}$ & $15,45 \mathrm{ab}$ & $8,01 \mathrm{a}$ & $23,89 \mathrm{a}$ & $1,04 \mathrm{c}$ \\
Imazethapyr & 0,10 & PRE & $30,31 \mathrm{a}$ & $11,84 \mathrm{~b}$ & $6,06 \mathrm{a}$ & $17,21 \mathrm{~b}$ & $7,39 \mathrm{ab}$ \\
Imazethapyr & 0,20 & PRE & $34,71 \mathrm{a}$ & $13,06 \mathrm{ab}$ & $5,11 \mathrm{a}$ & $16,03 \mathrm{~b}$ & $8,13 \mathrm{ab}$ \\
\hline
\end{tabular}

/1 - Dias após a aplicação dos herbicidas.

/2 - Plantas sem espiga.

/3 - Médias seguidas pela mesma letra na coluna, não diferem entre si pelo teste de Tukey a $5 \%$ de probabilidade.
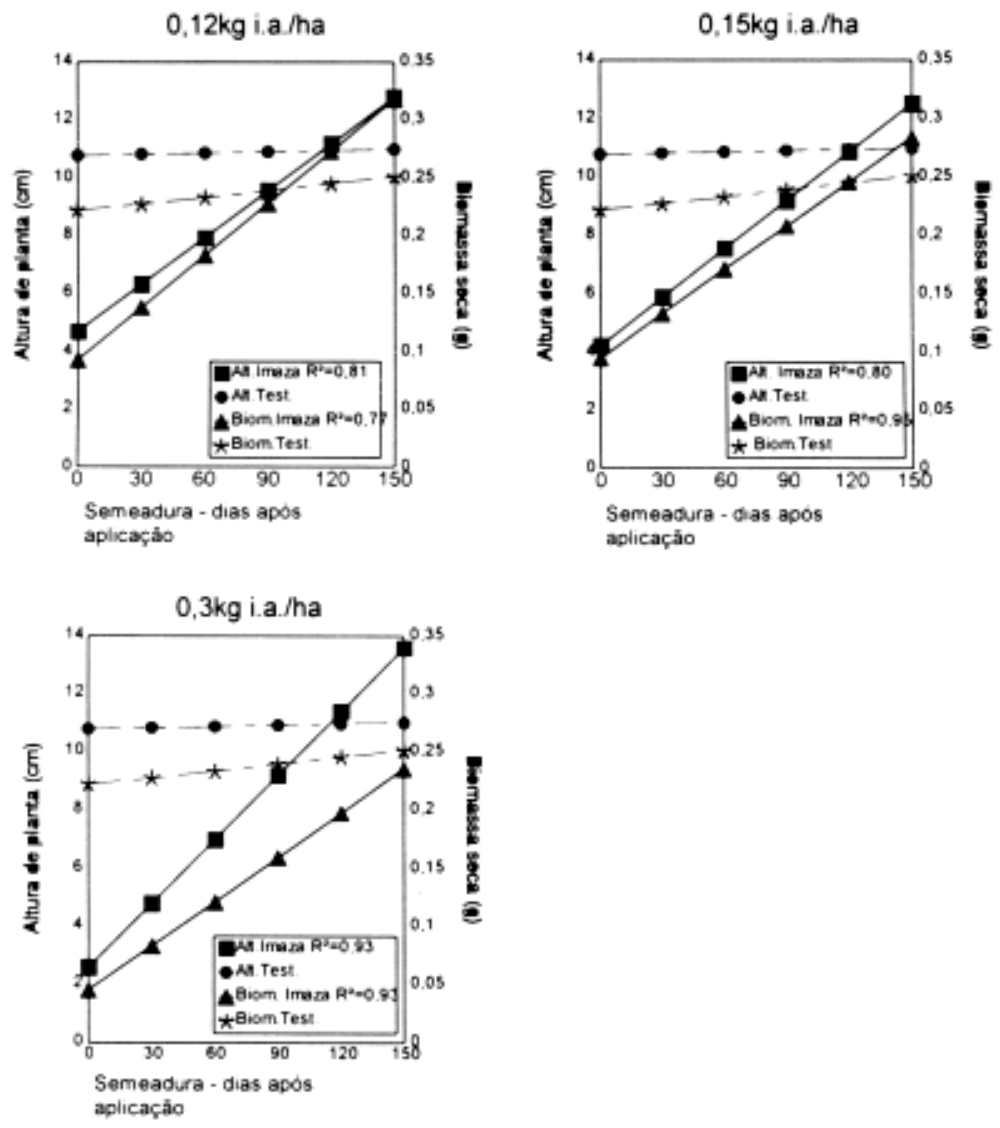

FIGURA 3. Biomass a seca e altura de plantas de pepino, quando submeti das a diferentes doses de imazaquin, comparado com a testemunha. Embrapa Soja. Londrina - PR, 1997. 
No segundo experimento, nas avaliações da biomassa seca e altura das plantas de pepino, semeadas em solos tratados com diferentes doses de imazaquin, foram necessários 120 dias para eliminar qualquer efeito do produto sobre a planta reagente com as doses de 0,12 e $0,15 \mathrm{~kg} / \mathrm{ha}$ (Figura 3). Com o dobro da dose recomendada $(0,3 \mathrm{~kg} / \mathrm{ha})$, aos 120 dias, não foi detectado efeito sobre altura, mas a biomassa seca baixa indicava haver persistência do produto.

Com imaze thapy r aplicado em pós emergência tanto na dose normal, $0,1 \mathrm{~kg} / \mathrm{ha}$, como na dose dobrada, foram necessários 150 dias para desaparecerem os efeitos sobre a altura das plantas de pepino. No entanto, este mesmo período não foi suficiente para a recuperação da biomassa seca das plantas (Figura 4). Na aplicação de imazethapyr em pré-emergência, com a dose normal, a altura das plantas não foi mais afetada pelo produto persistente no solo aos 90 dias da aplicaçã o, mas foram nece ssários 150 dias para que a biomassa seca fosse igual ao da testemunha. Com o dobro da dose $(0,2 \mathrm{~kg} / \mathrm{ha})$, tanto a altura como a biomassa seca foram inferiores aos da testemunha após 150 dias da aplicação. Este resultado mostra que as plantas de pepino são mais sensíveis ao imazethapyr que as plantas de milho, uma vez que mesmo não havendo sintomas de fitotoxicidade no milho aos 150 dias após a aplicação $(0,2 \mathrm{~kg} / \mathrm{ha}$ - pré) ainda se observou efeit o do produto sobre a altura e biomassa seca das plantas de pepino na mesma época.
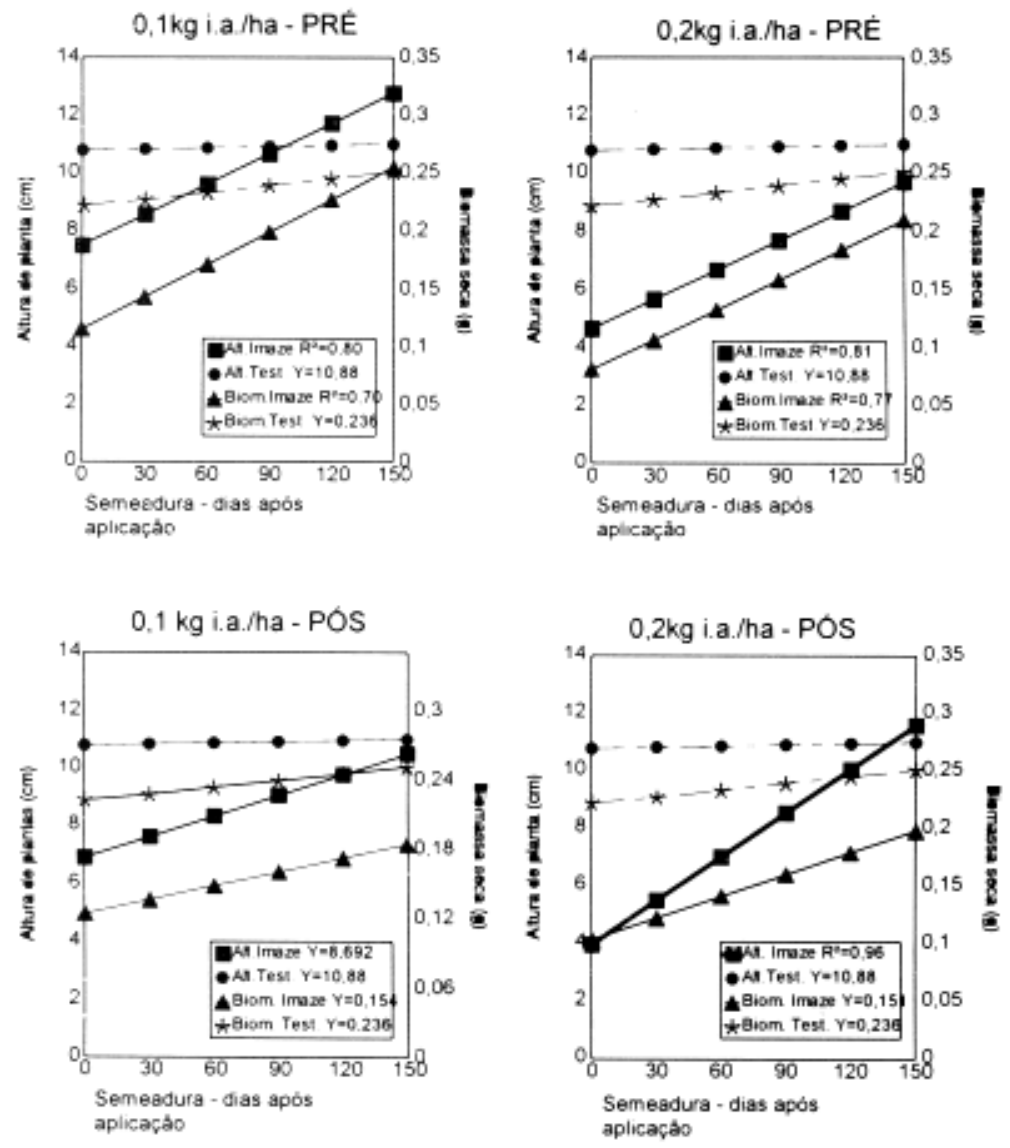

FIGURA 4. Biomassa seca e altura de plantas de pepino, quando submetidas a diferentes doses e épocas de aplicação de imazethapyr, comparado com a testemunha. Embrapa Soja. Londrina - PR, 1997. 


\section{AGRADECIMENTOS}

Os au to re s ag radece m aos té cn icos agrícolas Mario Nakano e Reinaldo Moriyama pela dedicação.

\section{LITERATURA CITADA}

BASHAN, G.W., LAVY T.L. Microbial and photolytic dissipation of imazaquin in soil Weed Sci., v.35, p.865-870, 1987.

CURRAN, W'.S., KNAKE, E.L., LIEBL, R.A. Corn (Zea mais) injury following use of clomazone, chlorimuron, imazaquin and imazethapyr. Weed Tecnol., v.5, p.539-544, 1982.
FLECK, N.G., VIDAL, R.A. Injúria potencial de herbicidas de solo ao giras sol. III - imazaquin e imaze thapyr. Planta Daninha, v.12, p. 39 43, 1994.

LOUX, M.M., REESE, K.D. Effect of soil $\mathrm{pH}$ on adsorption and persistence of imazaquin. Weed Sci., v.40, p.490-496, 1993.

LOUX, M.M., LIEBL, R.A., SLIFE, F.W. Availability and persistence of imazaquin, imazethapy $r$ and clomazone in soil. Weed Sci., v.37, p.259-267, 1989.

VIDAL, R.A., FLECK, N.G. Injúria potencial de herbicida de solo ao girassol IV Rendimento de aquênios e componentes do rendimento. Planta Daninha, v.12, p.44-51, 1994. 